Population Systems 
Alan A. Berryman - Pavel Kindlmann

\section{Population Systems}

A General Introduction

粤 Springer 
Alan A. Berryman

Washington State University

Pullman

USA
Pavel Kindlmann

Biodiversity Research Centre

Institute of Systems Biology and Ecology ASCR

České Budějovice

Czech Republic

Library of Congress Control Number: 2007941254

(C) 2008 Springer Science + Business Media B.V.

No part of this work may be reproduced, stored in a retrieval system, or transmitted in any form or by any means, electronic, mechanical, photocopying, microfilming, recording or otherwise, without written permission from the Publisher, with the exception of any material supplied specifically for the purpose of being entered and executed on a computer system, for exclusive use by the purchaser of the work.

Printed on acid-free paper

\section{$\begin{array}{lllllllll}9 & 8 & 7 & 6 & 5 & 4 & 3 & 2 & 1\end{array}$}

springer.com 


\section{Dedication}

To

Rachael, Ashley, Annie, Lucka and Petr

Our delightful contributions to the population problem and in memory of

Thomas Malthus

who saw the ultimate consequences 


\section{Preface to the First Edition}

I had taught courses in applied ecology, population dynamics, and population management for many years and, like many of my colleagues, had grown accustomed to the blank stares of my students as we wove our way through the confused semantics and intricate concepts of traditional ecology and wrestled with elaborate mathematical arguments. I searched in vain for a central unifying concept on which to organize a theory of population ecology until, 30 years ago, I read a small book of essays edited by John Milsum of McGill University entitled Positive FeedbackA General Systems Approach to Positive/Negative Feedback and Mutual Causality. Stimulated by the articles in this book, particularly those written by Milsum, M. Maruyama, and A. Rapoport, I began to structure my lectures around the central ideas of general systems theory. I first used this approach in my graduate courses in population dynamics and population management and then, encouraged by the results, in my undergraduate course in forest entomology and to teach population dynamics to practicing foresters. Almost without exception, my students found the general systems approach intuitively reasonable and easier to understand than traditional teaching methods. Even undergraduates seem to grasp the fundamental principles quite rapidly and, more important, to realize that a general understanding of population systems is an essential part of their education. These reactions by my students, and their continued encouragement, led me to write this book.

This book is concerned with the general principles and theories of population ecology. I have attempted to derive these from a basic understanding of how general systems behave together with observations of the behavior of real population systems. Unlike some of my colleagues, I am convinced that the rules governing the dynamics of populations are relatively simple, and that the rich behavior we observe in nature is a consequence of the structure of the system rather than of the complexity of the underlying rules. This is aptly demonstrated by the "Game of Life" discussed in Chapter 1. In this chapter I have tried to provide a basic framework for analyzing the structure and dynamics of systems in general, using a simplified interpretation of general systems theory. From this perspective we then examine the dynamic behavior of single-species populations in Chapter 2 and develop an elementary feedback model of the population system. In Chapter 3 this single-species model is refined and generalized by examining the mechanisms of population regulation, and graphical procedures are developed for evaluating the 
behavior of populations inhabiting variable environments. These graphical methods are then applied to the analysis of interactions between two species, including mutualistic, competitive, and predator-prey systems, in Chapter 4. Then, in Chapter 5 , we extend our dimensions to examine spatial effects on population behavior, and in Chapter 6 we take a brief look at communities composed of many interacting species.

Because I am convinced that all of us in this overcrowded world should be familiar with the basic concepts of population dynamics, I have attempted to write this book in a way that is comprehensible to the undergraduate student and layman, as well as being stimulating to the graduate student, professional population manager, and teacher. For this reason I have tried to avoid much of the ecological jargon and the complicated mathematics, which abound in the literature. The mathematics I have used is mostly elementary algebra, though more complicated arguments are presented, for those who wish to delve more deeply, in notes at the end of each chapter.

Although this book is of a theoretical nature, it is written with the applied ecologist and population manager in mind. At heart I am an applied ecologist, but I am also convinced that a firm theoretical background is essential if we are to make sound decisions concerning the management of our renewable resources and to anticipate the subtle consequences of these decisions. Managers frequently have to deal with population systems that are undefined, or only partly defined, by empirical data. Under these conditions they must rely on an intuitive understanding of the processes and interactions of the system. Population theory forms a basic framework on which this understanding can be built with the help of experience and an inquiring mind. This is not to say that a detailed knowledge of the properties and behavior of specific population systems, as well as the tactical tools available to the manager, are not equally important to the applied ecologist. Ideally this book should be used as a supplement to a specific text in courses aimed at the management of forest, range, wildlife, fish, or pest populations.

The theme throughout this book is populations interacting with their environments, and its main message is that populations of plants and animals can be intelligently managed if the general rules governing their behavior are clearly understood. If there is some urgency in my message it is because of my concern for this overcrowded planet and for our threatened renewable resources. Should this book contribute to our understanding of the immense problems we face, my time will have been well spent.
A. A. B.
Pullman
Washington
February 1980 


\section{Preface to the Second Edition}

In the early 1980's, when I was at the beginning of my carrier of a theoretical ecologist, I came across a blue book called Population Systems. The intuitive approach adopted here was clearly distinct from all other books on mathematical modeling of population dynamics available at that time. Instead of masses of equations, followed by calculation of equilibria and their stability, the topic was explained here using drawings of isoclines and reproduction planes and the reader was asked to use visualization (and sometimes even something like intuition) to predict the behavior of complex biological systems. Despite my previous training in mathematics, I was amazed by the amount of practical interpretations, which could be derived from the models by means of this purely "visual" approach. I began to understand that mathematicians, by using explicit forms of their equations, often indulge themselves in complicated calculations, which then obscure the biologically interesting predictions of their models.

I soon found I was not alone. Many of my colleagues oriented in theoretical ecology, which had been trained as biologists (including Tony Dixon, Vojta Jarošík and many other people mentioned below in the Acknowledgements), found this inconspicuous book very appealing for exactly the same reason - intuitive approach to the problem. The book, however, did remain alone for more than 25 years. At least, I am not aware of any other book using the reproduction plane approach to such an extent, as done in Population Systems. Thus I was not surprised, when Alan Berryman was invited to publish its second edition. And I was very much honored and excited, when he agreed to accept me as a co-author, who would contribute negligibly by helping him with the revision.

Thanks to the unique "reproduction plane" approach, the main text did not require any dramatic changes, as most of it still stands - even more than 25 years after is has first seen the light of the world! Admittedly, some expressions, like "if you have a programmable pocket calculator available", became rather obsolete. We decided to accompany the book with a CD, where the reader can find lots of useful EXCEL files, illustrating the statements made in the main text and showing some examples of continuous systems. We refer to this disk, whenever appropriate. The introductory file appears automatically after the CD has been put into the drive - and the student is then instructed about how to use the other 
files. We also added a few new references and examples, which were published since the first edition, but are aware that we certainly did not include all those worth citing.

We hope that this slightly updated version of the classic book might find its place in the fast-growing array of literature on mathematical ecology.

P. K.

České Budějovice

August 2007 


\section{Acknowledgments}

This book represents a synthesis of information and ideas obtained from many different sources, which have been blended with the particular (peculiar?) views of the senior author. The origins of many of these ideas have long been lost, but they include the contributions of well-known and unheralded ecologists, mathematicians, and systems scientists. The early thinking of the senior author was greatly influenced by his teachers, first at Cornwall Technical College, where Gordon Ince guided his birth as a biologist, and then at Imperial College of Science and Technology, London, and the University of California, Berkeley. At these latter schools his fascination with population ecology flourished under the tutelage of O. W. Richards, T. R. E. Southwood, N. Waloff, R. W. Stark, C. B. Huffaker, and D. W. Muelder. His interest in ecology developed during the Great Debate between A. J. Nicholson and H. G. Andrewartha, and their adherents, and it has been sustained and enriched by the contributions of C. S. Holling, R. M. May, R. Levins, and many, many others. As mentioned in the preface to the first edition, the conversion of the senior author to a general systems approach was brought about by reading the delightful book edited by J. H. Milsum, but his friend and colleague L. V. Pienaar also played an invaluable role in his education.

Many of the ideas presented in this book were forged by years of debate and argument with friends and colleagues. These sometimes vigorous personal interactions have provided the feedback which has nourished the thinking of the senior author and include discussions with A. S. Isaev, R. M. Peterman, G. E. Long, A. P. Gutierrez, K. J. Stoszek, D. L. Dahlsten, R. R. Sluss, E. C. Zeeman, J. A. Meyer, L. R. Ginzburg, M. P. Hassell, W. Baltensweiler, P. Carle, N. C. Stenseth, J. A. Logan, D. L. Wollkind and many others too numerous to mention. Hopefully they will not feel slighted by the failure to mention them by name. The graduate students of the first author have also contributed much to his thinking as their fresh young minds challenged conventional wisdom. He has taught them little but they have learned much together.

The junior author would like to mention two people at the first place: M. Rejmánek, who was the first person that introduced him to the concepts of mathematical biology, and A.F.G. Dixon, his lifetime friend and collaborator, who initiated his interest in modelling the life history strategies and whose ideas greatly influenced his further development as a scientist. The thinking of the junior author has also much profited from interesting and 
fruitful discussions with many colleagues, in the first place with (alphabetically): R. Arditi, K. Basnet, J. Baudry, F. Burel, J. Frouz, L. J. Gross, R. Harrington, J.-L. Hemptinne, M. Hulle, J. Lepš, A. Mackenzie, V. Novotný, J. S. Pierre, M. Plantegenest, R. B. Primack, D. Roberts, R. Tremblay, S. A. Ward, W. W. Weiser, D. F. Whigham, J. H. Willems and H. Yasuda. Personal interactions with other colleagues and students have provided him lots of intellectual stimuli and include discussions with (alphabetically): S. Aviron, Z. Balounová, S. Bečvář, B. Bhattarai, J. Blízek, C. N. Brough, P. Ceryngier, P. Cudlín, C. A. Dedryver, I. Dostálková, M. Grycz, F. Halkett, J. Havelka, I. Hodek, J. Holman, K. Houdková, V. Jarošík, P. Janečková, Y. Kajita, R. Kundu, Z. Mráček, O. Nedvěd, M. Okrouhlá, P. K. Paudel, J. Rajchard, P. Řezáč, A. Rico, Z. Růžička, S. Sato, R. Sequeira, P. Šmilauer, M. Špinka, K. Spitzer, B. Stadler, M. Stříteský, I. Stuchlíková, K. Wotavová, and many others.

They have all contributed, but three students of the senior author, G. C. Brown, K. F. Raffa, and R. H. Miller, and three students/colleagues of the junior author, O. Ameixa, J. Jersáková and I. Schodelbauerová, have given most because they read the book and made useful suggestions for its improvement. The book was also read by H. W. Li, R. W. Stark, A. P. Gutierrez, and D. R. Satterlund, and their constructive criticism and thoughtful suggestions have been of great help in preparing this manuscript. The book has also benefited from comments by students taking the graduate class in Population Management, and by professional foresters taking the short course in Population Dynamics in the U.S. Forest Service Continuing Education Program, both by the senior author, and particularly from the detailed review of P. J. Castrovillo.

Finally, we would like to thank those who kindly allowed us to use their original illustrations; W. C. Clark, D. D. Jones, and C. S. Holling and Plenum Press for Figure 5.4, C. B. Huffaker for Figure 5.8, and G. E. Long and Elsevier Scientific Publishing Company for Figure 5.12. All the other figures from published material were redrawn by J. Singleton and are acknowledged in their captions. We thank the authors for their permission to redraw their figures. The quotation from J. M. Keynes, which ends this book, was printed with the kind permission of Granada Publishing Ltd. The second edition was supported by the grant No. LC06073 of the MSMT.

A. A. B. and P. K. 


\section{Contents}

Preface to the First Edition ...................................................................... vii

Preface to the Second Edition ................................................................. ix

Acknowledgments ..........................................................................

\section{Part I Population Systems}

Introduction to Part I .........................................................................

Chapter 1 A Brief Look at Systems in General....................................... 3

1.1 What is a System? ........................................................... 3

1.2 The State of a System ............................................................. 6

1.3 Dynamical Systems ……………………………….......... 6

1.4 System Diagrams .............................................................. 7

1.5 Feedback Control............................................................... 9

1.6 The Stability of Systems ..................................................... 12

1.7 Anticipatory Feedforward.................................................. 15

1.8 Systems Analysis in Biology ............................................... 17

1.9 Chapter Summary .......................................................... 22

Exercises .................................................................... 23

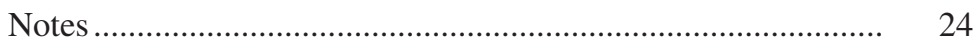

Chapter 2 Population Dynamics and an Elementary Model .................. 27

2.1 What is a Population? ....................................................... 27

2.2 Dynamics of Populations.................................................... 29

2.3 An Elementary Population Model .................................... 35

2.4 Analysis of the Model....................................................... 41

2.5 Environmental and Genetic Effects .................................. 47

2.6 Chapter Summary ……………………………….......... 48

Exercises ........................................................................... 50

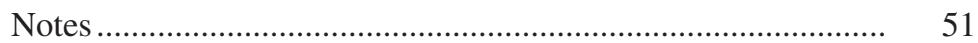


Chapter 3 Population Regulation and a General Model ..................... 57

3.1 Density-Dependent Mechanisms .................................... 57

3.1.1 Competitive Processes ....................................... 58

3.1.2 Cooperative Processes ...................................... 60

$3.2 \quad$ Feedback Integration ................................................. 62

3.3 A General Population Model ........................................... 65

3.4 Analysis of the Model............................................... 70

3.4.1 Environmental and Genetic Effects .................... 73

3.5 Populations in Changing Environments .......................... 75

3.5.1 Environmental Feedback ................................... 77

3.6 Complex Density-Dependent Relationships................... 79

3.7 Chapter Summary ...................................................... 83

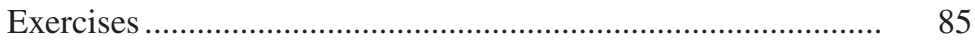

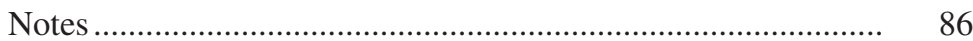

\section{Part II Systems of Interacting Populations}

Introduction to Part II

Chapter 4 Interactions Between Two Species.................................... 95

$4.1 \quad$ Population Interactions ................................................ 95

4.2 Cooperative Interactions ............................................... 96

4.3 Competitive Interactions................................................. 100

4.3.1 Nonlinear Competitive Interactions..................... 104

4.3.2 Competition in Variable Environments ................ 106

4.3.3 Strategies of the Competitor .............................. 109

4.4 Predator-Prey Interactions .......................................... 110

4.4.1 Nonlinear Predator-Prey Interactions .................. 115

4.4.2 Predator Functional Responses............................ 119

4.4.3 Predation in Variable Environments ..................... 124

4.4.4 Predator and Prey Strategies ............................. 126

4.5 Chapter Summary .................................................. 128

Exercises ............................................................................ 130

Notes ...................................................................... 132

Chapter 5 Interactions in Space .................................................... 149

5.1 Introduction.......................................................... 149

5.2 Movements in Space ...................................................... 150

5.3 Dynamics in Space ..................................................... 154

5.4 The Spread and Collapse of Pest Epidemics .................... 157

5.5 Stability in Space .............................................................. 161

5.6 Population Quality in Space ......................................... 164

5.7 Environmental Stratification.......................................... 167

5.8 Chapter Summary ........................................................ 170

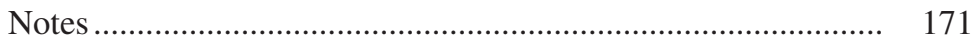


Chapter 6 Interactions Between Many Species

(Ecological Communities)

6.1 Community Structure .................................................... 177

6.2 Community Stability ........................................................ 179

6.2.1 Predation as a Stabilizing Influence ................... 187

6.3 Community Dynamics................................................. 189

6.4 Chapter Summary ........................................................ 193

Exercises ............................................................................. 195

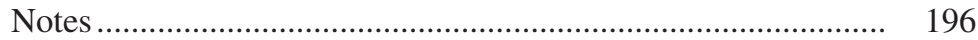

Epilogue: The Human Dilemma .................................................... 199

Answers to Exercises.................................................................................. 205

Name Index ............................................................................ 211

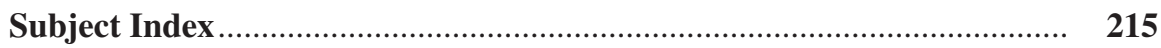

